\title{
Real-time ultrasound-guided thoracentesis in the intensive care unit: prevalence of mechanical complications
}

\author{
David Rene Rodriguez Lima ${ }^{1 *}$, Andrés Felipe Yepes², Claudia Inés Birchenall Jiménez², \\ Mario Andrés Mercado Díaz ${ }^{2}$ and Darío Isaías Pinilla Rojas ${ }^{2}$
}

\begin{abstract}
Background: The use of thoracic ultrasound during thoracentesis reduces complications. The aim of this study was to determine the prevalence of complications for real-time ultrasound-guided thoracentesis performed by intensivists. As a secondary objective, the change in oxygenation before and after the procedure was evaluated.

Patients and methods: An observational prospective study was conducted. A total of 81 cases of real-time ultrasound-guided thoracentesis performed by intensivists in the intensive care unit (ICU) of Méderi Major University Hospital, Bogotá, Colombia, between August 2018 and August 2019 were analyzed. Thoracentesis performed by interventional radiologists and using techniques different from the focus of this study were excluded from the analysis.

Results: There was one pneumothorax, for a prevalence rate of mechanical complications in this population of 1.2\%. The mean partial oxygen pressure to inspired oxygen fraction ratio $\left(\mathrm{PaO}_{2} / \mathrm{FiO}_{2}\right)$ prior to the procedure was 198.1 (95\% Cl 184.75-211.45), with a $\mathrm{PaO}_{2} / \mathrm{FiO}_{2}$ after the procedure of $224.6(95 \% \mathrm{Cl} 213.08-226.12)(p<0.05)$.

Conclusions: Real-time ultrasound-guided thoracentesis performed by intensivists is a safe procedure and leads to a significant improvement in oxygenation rates. Future studies are required to determine the impact of these results on other outcomes, such as mortality, ICU stay, and days of mechanical ventilation.
\end{abstract}

Keywords: Ultrasound, Thoracentesis, Complications, Intensive care

\section{Background}

Pleural effusion is a frequent finding in the intensive care unit (ICU), and it can cause hypoxemia and alterations in lung mechanics [1].

The prevalence of pleural effusion in the ICU can vary between 40 and $60 \%$ [2]. The commonly reported causes of pleural effusion in this population are infectious exudates (43\%), non-infectious exudates (33\%) and transudates $(24 \%)$ [3]. In postoperative patients undergoing cardiovascular surgery, up to $7 \%$ present with pleural effusion, the most common cause being hemothorax in

\footnotetext{
*Correspondence: drrodriguezl@hotmail.com

1 Emergency Medicine and Critical and Intensive Care Medicine, Hospital Universitario Mayor Méderi-Universidad del Rosario, Bogotá, Colombia
} Full list of author information is available at the end of the article up to $50 \%$ of cases, with dyspnea as the predominant symptom [4].

Pleural effusions with documented volumes greater than $500 \mathrm{ml}$ affect gas exchange, hemodynamic stability and respiratory work, and it has been demonstrated that drainage of pleural effusions in ICU patients under mechanical ventilation is related to improved oxygenation indices, increased end-expiratory volume and decreased transpulmonary pressure [5]. A recent metaanalysis that included 31 studies with 2265 patients showed that drainage of pleural fluid produces improvement in $\mathrm{PaO}_{2} / \mathrm{FiO}_{2}$ as an oxygenation index and tends to increase end-expiratory volume [6].

Thoracentesis is a percutaneous procedure for collecting pleural fluid, and it has diagnostic utility and therapeutic applications. It is recommended for pleural 
effusions of unknown cause, because it allows defining the cause of the effusion and has therapeutic utility in large-volume pleural effusions associated with respiratory distress [7]. Thoracentesis should not be performed for bilateral effusions in a clinical picture strongly suggestive of transudate (e.g., cardiac failure), unless the presentation is atypical or does not respond to clinical management $[8,9]$.

Complications related to the performance of blind thoracentesis include a high incidence of pneumothorax (11\%) [10]; for this reason, the use of ultrasound guidance is strongly recommended for performing interventions in the pleural space and using small-diameter catheters $[11,12]$. In turn, the diagnostic sensitivity of ultrasound for pleural effusion is higher compared to that of chest $\mathrm{X}$-ray and allows identifying the pleural fluid characteristics that differentiate complicated and uncomplicated effusions and homogeneous and heterogeneous effusions [13]. In addition, the routine implementation of pulmonary ultrasound in the ICU decreases the number of chest X-rays, with a reduction in medical costs and radiation exposure, without affecting the clinical results [14].

Various techniques have been developed to estimate the volume of pleural fluid by ultrasound, with a good correlation between the drained liquid and that calculated prior to the procedure, finding that distances between the diaphragm and the visceral pleura greater than $30 \mathrm{~mm}$ are related to pleural effusions greater than $500 \mathrm{ml}$ [15]. Balik et al. described a formula to calculate the pleural effusion volume by ultrasound by measuring the maximal interpleural distance (Sep) in millimeters $(\mathrm{mm})$ in end-expiration at the lung base in a posterior axillary line and multiplying this value by 20 , quantifying the pleural fluid volume ( $\mathrm{Vpl})$ in milliliters $(\mathrm{ml})$ [16]. The method described by Balik et al. was validated in patients under invasive mechanical ventilation in a supine position with mild trunk elevation at $15^{\circ}$; however, the mean prediction error of this equation is high $(158 \pm 160 \mathrm{ml})$ $[16,17]$. The position of the patient influences the volume calculated by this method because when elevating the headboard, the free pleural fluid experiences the effects of gravity and can increase the interpleural distance [18]. In Balik et al's original work, no difference in correlation of interpleural distance with the right- and left-side drained volumes was found [16]; however, other studies have found a better correlation on the right side [19, 20]. This is secondary to the fact that on the left side, the heart increases the level of a pleural effusion, like a stone in a container with water, leading to overestimation of the interpleural distance [18].

The aim of this observational study was to determine the prevalence of complications of real-time ultrasoundguided thoracentesis performed by intensivists. As a secondary objective, the change in oxygenation before and after the procedure was evaluated.

\section{Patients and methods}

Méderi Major University Hospital (Hospital Universitario Mayor Méderi) is a Colombian high-complexity hospital with 780 hospital beds and 97 adult ICU beds where routine use of ultrasound for the performance of guided procedures by intensivists has been implemented for 5 years.

During a period of 13 months (between August 2018 and August 2019), data were collected prospectively from 81 consecutive real-time ultrasound-guided thoracentesis performed by intensivists in the ICU of Méderi Major University Hospital, Bogota, Colombia. Patients undergoing thoracentesis using methods other than real-time ultrasound-guided techniques and those in whom thoracentesis was performed by interventional radiologists were excluded from the analysis. Authorization for this study was granted by the Institutional Human Research Ethics Committee of Del Rosario University (DVO005 1068-CV1177).

All thoracentesis were performed by intensivists with more than 5 years of experience, who during their graduate education had at least 1 month of certified ultrasound training. The decision to perform thoracentesis was made only for clinical reasons and was not based on the protocol.

Pleural effusion is diagnosed by portable chest X-ray findings (anteroposterior view and supine position), pleural ultrasound or chest tomography according to the clinical applicability for each patient. If the treating physician considered the patient to be a candidate for drainage, an assessment was performed by an intensivist with experience in thoracic ultrasound. This professional performed the thoracic ultrasound, evaluating the chest wall in eight areas as recommended by the International Evidence-Based Recommendations for point-of-care lung ultrasound [21] to confirm the presence of pleural effusion and to determine whether it was susceptible to drainage.

Estimation of the pleural effusion volume $(\mathrm{Vpl})$ in $\mathrm{ml}$ was performed similarly to the method described by Balik et al:: $\mathrm{Vpl}(\mathrm{ml})=\operatorname{Sep}(\mathrm{mm}) * 20$; however, the majority of patients included in this study were not under mechanical ventilation and showed little tolerance to the supine position at $15^{\circ}$, and therefore, the investigators decided to perform the measurement with the trunk elevated to $30^{\circ}$ regardless of whether the patient was under invasive mechanical ventilation or spontaneous breathing.

The technique used is similar to that described by Vertrugno et al. [22] and was carried out as follows:

For the procedure, a SonoSite M-Turbo ultrasound machine with a $5-\mathrm{MHz}$ small-footprint convex 
transducer and a $13-\mathrm{MHz}$ linear transducer were used. The real-time ultrasound-guided thoracentesis technique used for the patients included in this study is described below (Figs. 1, 2 and 3):

1. The thoracentesis kit, which contains antiseptic solution, sterile gloves, sterile gauze, local anes- thetic, intramuscular needle, subcutaneous needle, 5-, 10-, and 50-ml syringes, 3-way stopcock, 16 gauge thoracentesis needle, 6 -French pigtail thoracic drainage catheter, $0.38^{\prime \prime} \times 80 \mathrm{~J}$-tip metal guide, $6 \mathrm{Fr}$ dilator, scalpel, silk to fasten the catheter and collection bag, is prepared.
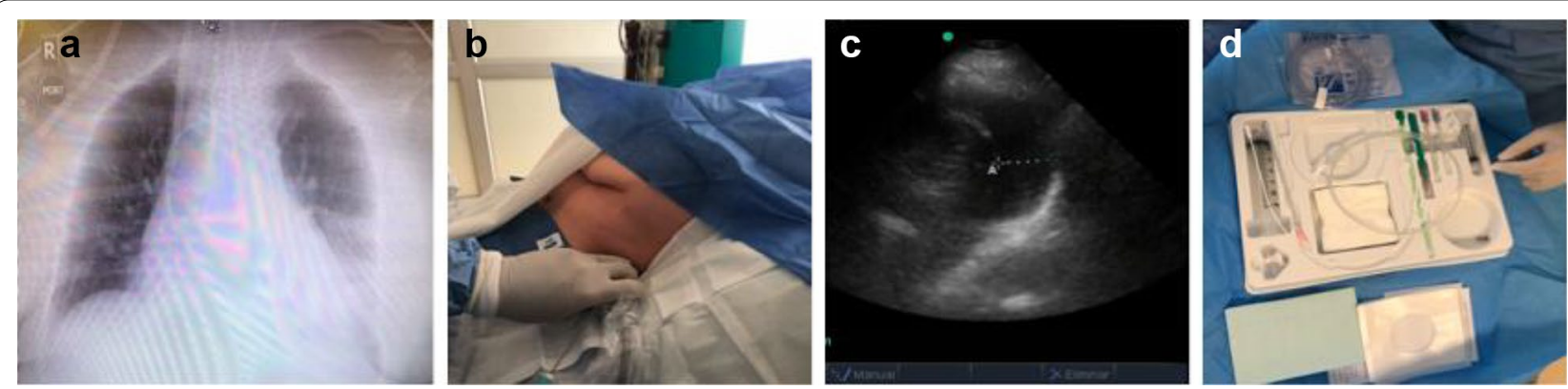

Fig. 1 a Chest $X$-ray of the patient with left pleural effusion during the postoperative period of myocardial revascularization. $\mathbf{b}$ Patient in the supine position with the head at $30^{\circ}$; ultrasound assessment in the lower thorax on the posterior axillary line. $\mathbf{c}$ Quantification of the pleural effusion with a $5-\mathrm{MHz}$ convex transducer; measurement of the distance between the visceral pleura and the posterior wall of the thorax in the transverse axis. In this case, the distance is $26 \mathrm{~mm}$, with an approximate calculated volume of $520 \mathrm{ml}$ by the Balik method. $\mathbf{d}$ Thoracentesis kit
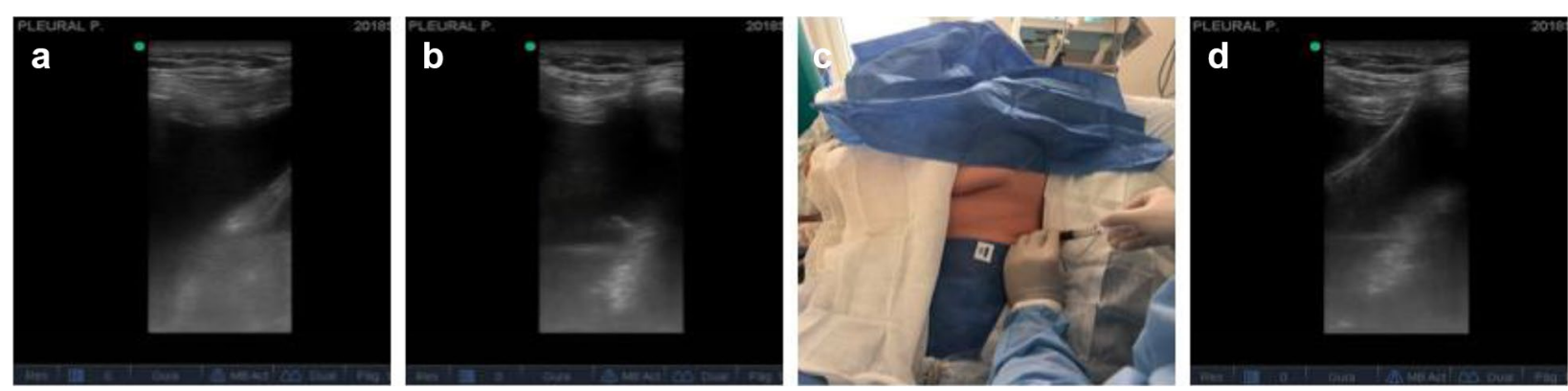

Fig. 2 a Assessment, with a 13-MHz linear transducer, of the effusion in the lower aspect of the thorax on the posterior axillary line, visualizing the upper and lower ribs, intercostal space, pleural fluid, and diaphragm. b After verifying no interposition of vessels with color Doppler, needle puncture is performed; needle passage into the pleural cavity is visualized in real time. c Pleural fluid return is verified, in this case blood. $\mathbf{d}$ Passage of the guide toward the pleural cavity on the diaphragm
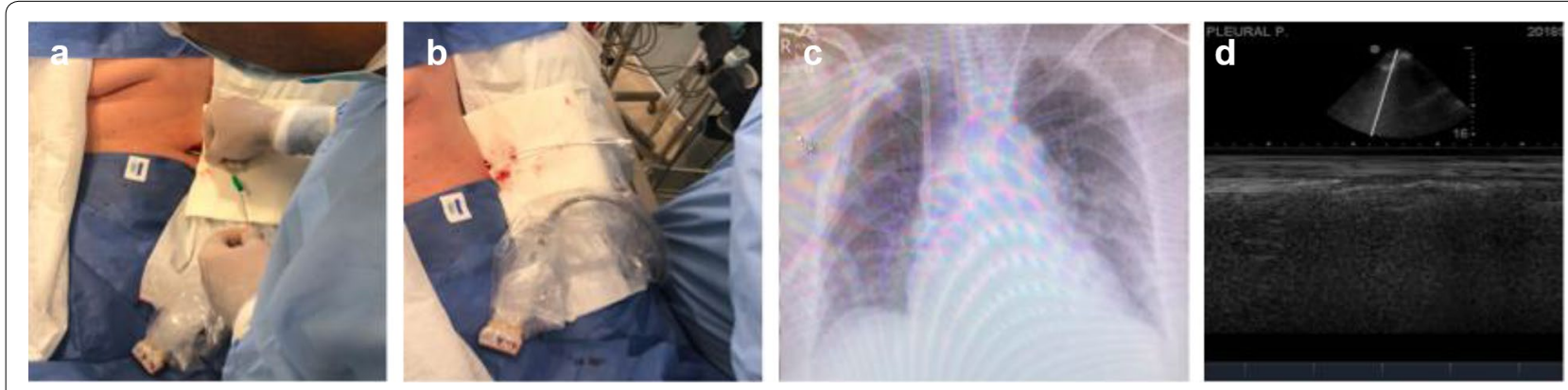

Fig. 3 a Passage of the dilator (between 1 and $2 \mathrm{~cm}$ ), depending on thoracic wall thickness. b Passage of the pigtail catheter to begin drainage. $\mathbf{c}$ Chest X-ray after drainage showing a fluid-free pleural cavity. $\mathbf{d}$ Ultrasound verification, with a sector transducer, of a fluid-free pleural cavity, also dismissing the presence of pneumothorax ("sand-on-the-beach"sign) 
2. The patient is placed in the supine position with the headboard at $30^{\circ}$.

3. The pleural effusion is visualized with a $5-\mathrm{MHz}$ convex transducer in longitudinal position at the lung base in a posterior axillary line.

4. Once the pleural effusion is visualized, the transducer is rotated to obtain a transverse view.

5. The distance between the visceral pleura and the posterior chest wall is measured.

6. If the distance is greater than $15 \mathrm{~mm}$, the patient is a candidate for the procedure.

7. After asepsis and antisepsis, with the linear transducer in the longitudinal direction, the transducer is positioned on the posterior axillary line in order to obtain an image of the diaphragm between two ribs.

8. Using color Doppler, it is verified that there is no blood vessel interposition.

9. Thoracentesis needle puncture (16 gauge) is performed over the center of the transducer in real time by visualizing needle insertion the entire time.

10. Once the pleural cavity is entered and fluid is collected, the metal guide is inserted, and its position is verified sonographically.

11. Then, the dilator is passed by inserting it 1 to $2 \mathrm{~cm}$, depending on the thickness of the chest wall.

12. The dilator is removed, and the pigtail catheter is inserted over the guide.

13. Once the pigtail catheter is inserted, the drainage system is connected to a 3-way stopcock with one connection directed toward the drainage bag and the other toward a 50-ml syringe. Active drainage is started with the $50-\mathrm{ml}$ syringe, without creating negative pressure that exceeds $-20 \mathrm{cmH}_{2} \mathrm{O}$ to avoid complications [10]. Importantly, during thoracentesis, the pleural and intrathoracic pressure decrease and the left ventricular afterload increases with a decrease in left ventricular systolic performance, and patients with moderateto-severe left ventricular dysfunction can develop pulmonary edema [23]. After the procedure, ultrasound is used to determine if residual fluid remains and to rule out the presence of pneumothorax. A chest X-ray performed within $24 \mathrm{~h}$ of the procedure is reviewed.

Demographic and clinical variables (macroscopic description of the pleural fluid, amount of drained fluid, interpleural distance, and possible cause), complications and procedure indications were analyzed. The presence of complications was ruled out by performing a lung ultrasound at the end of the procedure and reviewing a chest $\mathrm{X}$-ray performed within $24 \mathrm{~h}$ after the thoracentesis.
In cases of hemothorax in postoperative cardiac surgery patients, given that there could be confusion as to whether it was residual or associated with thoracentesis, after draining blood from the pleural space, no recurrence of hemothorax after the procedure was verified by ultrasound and on the chest X-ray taken on the following day. The indications for the procedure were classified as diagnostic if the objective of the procedure was only sampling to clarify the etiology of the effusion and as therapeutic if thoracentesis was performed because the patient was considered to have respiratory distress or hypoxemia secondary to the effusion.

A univariate analysis of categorical and continuous variables was performed; normality was tested with the Kolmogorov-Smirnov test. The paired samples $t$ test or the Wilcoxon signed rank test was performed. A value of $p<0.05$ was considered significant. The analysis was performed in STATA 14.

\section{Results}

A total of 81 ultrasound-guided thoracentesis were performed with the described technique. In the study period, $61.7 \%$ of the patients were men, and $38.3 \%$ were women; the mean age of the observed group was 67 years ( $\mathrm{SD} \pm 14$ years). In $96 \%$ of cases, the indication for thoracentesis was therapeutic, and only $3.7 \%$ of patients underwent the procedure as part of their diagnostic algorithm. The diagnoses presented by these patients were, for the most part, postoperative cardiovascular surgery $(56.8 \%)$, followed by heart failure (16\%), pneumonia (12.3\%) and others (14.8\%), among which paraneoplastic pleural effusion was noteworthy (Table 1).

The following macroscopic characteristics of the drained fluid were observed: evidence of a hemotho$\operatorname{rax}(55.6 \%)$, citrine $(29.6 \%)$, chylous $(6.2 \%)$, purulent (7.4\%) and paraneoplastic (1.2\%). Of the 46 cardiovascular surgery patients who underwent thoracentesis, 38 (82\%) had a hemothorax (Table 2).

\begin{tabular}{llll}
$\begin{array}{l}\text { Table } 1 \text { Diagnoses presented in ICU patients that led } \\
\text { to thoracentesis }\end{array}$ & $\begin{array}{l}\text { Absolute } \\
\text { frequency } \\
(\boldsymbol{n = 8 1 )}\end{array}$ & $\begin{array}{l}\text { Relative } \\
\text { frequency } \\
(\boldsymbol{n}=\mathbf{8 1})\end{array}$ & $\begin{array}{l}\text { Accumulated } \\
\text { percentage } \\
(\boldsymbol{n}=\mathbf{8 1})\end{array}$ \\
\hline \multicolumn{4}{l}{$\begin{array}{l}\text { Cardiovascular } \\
\quad \text { surgery }\end{array}$} \\
$\begin{array}{l}\text { Heart failure } \\
\text { Pneumonia }\end{array}$ & 13 & 56.8 & 56.8 \\
Other & 10 & 16.0 & 72.8 \\
\hline
\end{tabular}


Table 2 Appearance of the pleural fluid drained from the ICU patients

\begin{tabular}{llll}
\hline & $\begin{array}{l}\text { Absolute } \\
\text { frequency } \\
(\boldsymbol{n = 8 1 )}\end{array}$ & $\begin{array}{l}\text { Relative } \\
\text { frequency } \\
(\boldsymbol{n = 8 1 )}\end{array}$ & $\begin{array}{l}\text { Accumulated } \\
\text { percentage } \\
(\boldsymbol{n}=\mathbf{8 1})\end{array}$ \\
\hline $\begin{array}{l}\text { Appearance of the drainage } \\
\text { Hemothorax }\end{array}$ & 45 & & \\
Citrine & 24 & 55.6 & 55.6 \\
Chylous & 5 & 29.6 & 85.2 \\
Purulent & 6 & 6.2 & 91.4 \\
Paraneoplastic & 1 & 7.4 & 98.8 \\
\hline
\end{tabular}

All performed thoracentesis were successful, with one pneumothorax and no hemothorax observed, for a prevalence rate of mechanical complications in this population of $1.2 \%$. The pneumothorax presented in a 77 -year-old man not receiving mechanical ventilation, who required diagnostic thoracentesis, had a maximal interpleural distance of $15 \mathrm{~mm}$ and, for management, required the passage of a chest tube with drainage of $200 \mathrm{cc}$ of purulent fluid.

The mean $\mathrm{PaO}_{2} / \mathrm{FiO}_{2}$ presented positive variations in relation to the measurement at admission $(\mathrm{p}<0.05)$. Prior to the procedure, the $\mathrm{PaO}_{2} / \mathrm{FiO}_{2}$ was $198.1(\mathrm{SD} \pm 12.3)$ (95\% CI 184.75-211.45), and after the procedure, it was 224.6 (SD \pm 52.9$)(95 \%$ CI 213.08-226.12) (Table 3, Fig. 4). The stratified analysis showed that this improvement in $\mathrm{PaO}_{2} / \mathrm{FiO}_{2}$ was maintained in the subgroups regardless of the diagnosis $(p<0.05)$.

Regarding the characteristics of the procedure, drainage was located on the right side in $54.3 \%$ and on the left side in $45.7 \%$. Drainage was therapeutic in $96.3 \%$ of cases, the median amount drained was $900 \mathrm{ml}(95 \% \mathrm{CI}$ $900-1100 \mathrm{ml}$ ), and the pleural effusion volume estimated by the Balik et al. equation was $710 \mathrm{ml}$ (95\% CI 600 $1000 \mathrm{ml}$ ) (Table 4). Spearman's rho correlation analysis showed a moderate positive relationship between the amount drained and the estimated volume pre-thoracentesis $(r h o=0.573) \quad(p<0.05)$; when differentiating the sides, the correlation between the drained amount and the estimated volume was significant only for the right side $(\mathrm{rho}=0.7308, p<0.05)$, i.e., not for the left side (rho $=0.3776, p>0.05)$.

Of the total number of patients undergoing thoracentesis, $28.4 \%$ were on mechanical ventilation, and the median time to extubation was 6 days (95\% CI 5-12 days). For the 23 patients on mechanical ventilation, the $\mathrm{PaO}_{2} /$ $\mathrm{FiO}_{2}$ prior to the procedure was $184.3( \pm 48.37)(95 \% \mathrm{CI}$ 163.39-205.22), with a $\mathrm{PaO}_{2} / \mathrm{FiO}_{2}$ after the procedure of 205.82 ( \pm 57.38$)$ (95\% CI 181.01-230.64), maintaining the positive variation but without statistical significance $(p=0.08)$. Of these 23 patients, $11(47.8 \%)$ returned to spontaneous breathing within 7 days after thoracentesis, and in 10 (43.4\%), mechanical ventilation was prolonged beyond 1 week. Two patients (8.7\%) died in this period. For the 11 patients who achieved early extubation after drainage, the mean $\mathrm{PaO}_{2} / \mathrm{FiO}_{2}$ before and after the procedure was 222.81 ( $\mathrm{SD} \pm 40.67$ ) (95\% CI 195.49-250.13) and 240.44 (SD \pm 50.77 ) (95\% CI 206.33-274.55), respectively. For the 10 patients in whom early extubation was not achieved after drainage, the mean $\mathrm{PaO}_{2} / \mathrm{FiO}_{2}$ values before and after the procedure were $196.40(\mathrm{SD} \pm 60.46)$ (95\% CI 153.15-239.65) and 228.12 (SD \pm 70.66$)$ (95\% CI 177.58-278.60), respectively.

\section{Discussion}

This study shows that real-time ultrasound-guided thoracentesis performed by intensivists at the bedside is a safe procedure, with a prevalence rate of complications of $1.2 \%$, lower than that reported in the literature when blind pleural aspiration is performed, where the presence of pneumothorax ranges from 10 to $18 \%[12,24,25]$.

The safety of ultrasound-guided thoracentesis has been evaluated in other studies, and it is the recommended technique for this procedure by different international guidelines [12]. Barnes et al. [24] and Gervais et al. [26], in retrospective studies on ultrasound-guided thoracentesis performed by interventional radiologists, reported pneumothorax rates of $4.9 \%$ and $2.3 \%$, respectively. Petersen et al. [27] reported a series of 338 ultrasoundguided thoracentesis in the ICU, with four pneumothoraces (1.2\%). Lichtenstein et al. [28] and Mayo et al. [29] reported pneumothorax rates in patients receiving mechanical ventilation of 0 and $1.3 \%$, respectively.

Table 3 Pre- and post-thoracentesis oxygenation parameters in the ICU patients

\begin{tabular}{|c|c|c|c|c|}
\hline & Mean $(n=81)$ & $\begin{array}{l}\text { Standard deviation } \\
(n=81)\end{array}$ & Minimum $(n=81)$ & $\begin{array}{l}\text { Maximum } \\
(n=81)\end{array}$ \\
\hline $\mathrm{PaO}_{2} / \mathrm{FiO}_{2}$ prior to the procedure & 198.1 & 61.3 & 74.0 & 385.0 \\
\hline $\mathrm{PaO}_{2} / \mathrm{FiO}_{2}$ after the procedure & 224.6 & 52.9 & 110.0 & 385.0 \\
\hline Change in $\mathrm{PaO}_{2} / \mathrm{FiO}_{2}$ & 29.1 & 46.4 & -84.0 & 157.0 \\
\hline
\end{tabular}




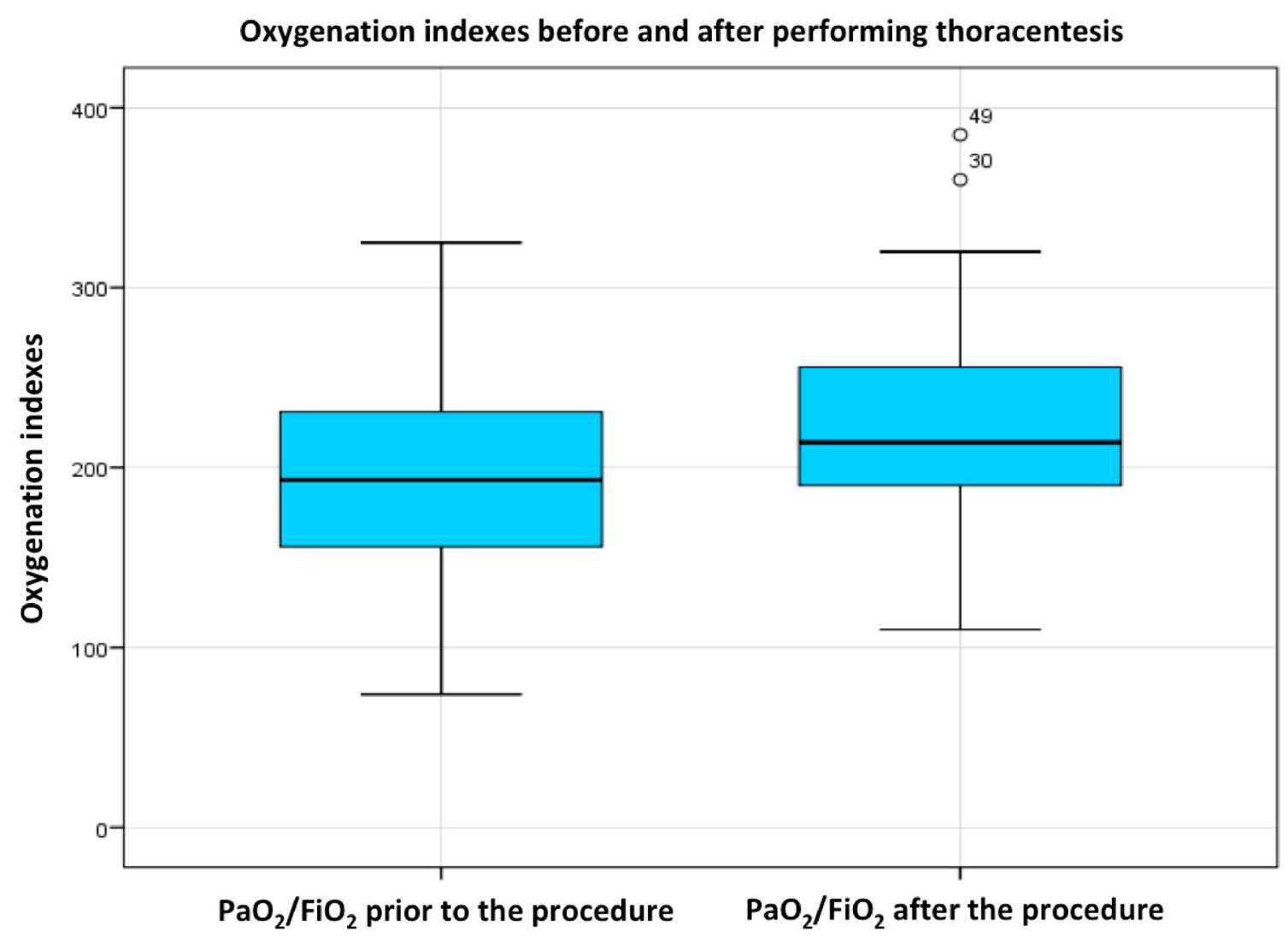

Fig. 4 Oxygenation indexes before and after performing thoracentesis. The average $\mathrm{PaO}_{2} / \mathrm{FiO}_{2}$ before the procedure was 198.1, and the average $\mathrm{PaO}_{2} / \mathrm{FiO}_{2}$ after the procedure was 224.6, $p<0.05$

Table 4 Amount of drainage in milliliters $(\mathrm{ml})$, interpleural distance prior to procedure in millimeters (mm), volume estimated using Balik's method

\begin{tabular}{llll}
\hline & Median $(\mathbf{n = 8 1 )}$ & Median 95\% Cl $(\mathbf{n = 8 1 )}$ & $\begin{array}{l}\text { Interquartile } \\
\text { range } \\
(\boldsymbol{n}=\mathbf{8 1})\end{array}$ \\
\hline Drained amount $(\mathrm{ml})$ & & & $550-1100$ \\
Distance $(\mathrm{mm})$ & 900 & $900-1100$ & $28-58.5$ \\
Estimated volume $(\mathrm{ml})$ & 35.5 & $30-50$ & $560-1170$ \\
Drained amount, right $(\mathrm{ml})$ & 710.0 & $600-1000$ & $550-1150$ \\
Distance, right $(\mathrm{mm})$ & 900 & $650-1000$ & $25-62$ \\
Estimated volume, right $(\mathrm{ml})$ & 32.5 & $26.86-50.83$ & $500-1240$ \\
Drained amount, left $(\mathrm{ml})$ & 650 & $537.21-1016.72$ & $550-1100$ \\
Distance, left $(\mathrm{mm})$ & 800 & $700-947.13$ & $30-57$ \\
Estimated volume, left $(\mathrm{ml})$ & 47.5 & $30-54.95$ & $600-1140$ \\
\hline
\end{tabular}

In these two studies, the procedure was performed in patients under mechanical ventilation. In comparison with those studies, the prevalence of complications reported in the present study is similar or lower.

Another important finding is the impact on oxygenation indexes after pleural drainage, evidencing post-procedure improvement in the $\mathrm{PaO}_{2} / \mathrm{FiO}_{2}(p<0.05)$, in agreement with that reported by Vertrugno et al. [10] and Goligher et al. [30]. In this study, the group of patients on mechanical ventilation was small (28.4\%), and of those in whom extubation was achieved in the first 7 days after thoracentesis, the $\mathrm{PaO}_{2} / \mathrm{FiO}_{2}$ post-procedure 
was higher, but not statistically significant, than in those with prolonged mechanical ventilation. These data suggest that patients in whom drainage led to a greater increase in $\mathrm{PaO}_{2} / \mathrm{FiO}_{2}$ were successfully weaned from mechanical ventilation earlier, as reported by Vertrugno et al. [20]. Further studies are needed to evaluate the importance of oxygenation indices in clinical benefits and outcomes after thoracentesis.

The median volume of drained fluid was $900 \mathrm{ml}$, and it is known that when volumes greater than $500 \mathrm{ml}$ are drained, oxygenation indices improve [8]. Interestingly, in the postoperative cardiovascular surgery patient subgroup, the benefit of improvement in oxygenation indices was maintained, which is important because it has been reported that the incidence of clinically significant pleural effusion in this group of patients is approximately $7 \%$ and in whom almost $50 \%$ of the fluid drained is hemorrhagic [4].

Spearman's rho correlation analysis showed a moderate positive linear relationship $(\mathrm{rho}=0.573)$ between the drained amount and the estimated volume; however, this correlation was lower than that described by Balik et al. [16], which can be explained by the fact that in this study, the estimate was applied to patients with spontaneous breathing and with the headboard at $30^{\circ}$. However, when analyzing each side separately, the correlation between the drained amount and the estimated volume was significant only on the right side $(r h o=0.7308)$ and not on the left side $(r h o=0.3776)$, which can be explained by the presence of the heart, as it increases the pleural effusion level, leading to an overestimation of the calculated volume $[17,18]$.

The intensivists who performed thoracentesis during this study have more than 5 years of experience in the use of ultrasound at the bedside, and during their residency program, they were trained to perform ultrasoundguided procedures, which helps to explain the low rate of complications reported in this study. To begin performing thoracentesis in real scenarios, we first recommend the development of this skill in phantom models of lung anatomy [31].

This study has the strength of being the first series in which the majority of thoracentesis procedures were performed under ultrasound guidance in real time by intensivists, confirming the safety of this technique and the improvement in oxygenation indices.

This study is observational and has limitations. A lung ultrasound was not performed on all ICU patients during the study period; therefore, the proportion of pleural effusions that required drainage could not be reported. This study also does not allow assessing the safety of thoracentesis performed by other ultrasoundguided techniques, such as radiological marking and subsequent drainage by a different physician or marking and immediate puncture.

\section{Conclusions}

Real-time ultrasound-guided thoracentesis performed by intensivists is a safe procedure with a low complication rate compared to that for blind techniques, has a complication rate similar to that for other ultrasoundguided techniques and leads to significant improvement in oxygenation rates. Future studies are needed to determine the impact of these results on outcomes such as mortality, length of ICU stay and days of mechanical ventilation.

\section{Abbreviations}

ICU: Intensive care unit; SD: Standard deviation; ml: Milliliters; mm: Millimeters; $\mathrm{PaO}_{2} / \mathrm{FiO}_{2}$ : Partial pressure arterial oxygen/fraction of inspired oxygen; Sep: Maximal interpleural distance; Vpl: Pleural fluid volume.

\section{Acknowledgements}

Does not apply.

\section{Authors' contributions}

DRRL, AFY, MAMD, DIPR collected data and contributed to writing the manuscript. CIBJ performed the statistical analysis of the information and contributed to writing the manuscript. All authors read and approved the final manuscript.

\section{Funding}

Méderi Major University Hospital (Hospital Universitario Mayor Méderi) funded the collection, analysis, and interpretation of the data in this manuscript.

\section{Availability of data and materials}

All data used and analyzed during this study are available to be sent by email at the request of the editorial committee, anonymously and coded.

\section{Ethics approval and consent to participate}

This work is in line with the recommendations for biomedical research of the Declaration of Helsinki of the World Medical Association and is based on the regulations set forth in Resolution No. 008430 of 1993 (October 4, 1993) of the Colombian Ministry of Health, which establishes the academic, technical, and administrative standards for health research. According to article 11 of Resolution 8430 of 1993 of the Ministry of Health, which establishes the scientific technical, and administrative standards for health research, this research is classified as risk-free research because it uses documentary research techniques and retrospective methods and there is no intervention or intentional modification of the biological, physiological, psychological, or social variables of individuals participating in the study. The use of this information was approved and evaluated by the Research Technician of Méderi Major University Hospital (Hospital Universitario Mayor Méderi) and the Ethics Committee of Del Rosario University (Universidad del Rosario) (DVO005 1068-CV1177).

\section{Consent for publication}

Each patient or legal representative signed a general institutional informed consent form upon admission to the intensive care unit of Méderi Major University Hospital (Hospital Universitario Mayor Méderi) in which he/she expresses his/her will to allow the use of clinical history data, diagnostic images, photographs and the publication of this information for academic purposes. It is specified in this consent that all information that can identify or correlate to the person will be anonymized to guarantee their confidentiality.

\section{Competing interests}

The authors declare that they have no competing interests. 


\author{
Author details \\ ${ }^{1}$ Emergency Medicine and Critical and Intensive Care Medicine, Hospital Uni- \\ versitario Mayor Méderi-Universidad del Rosario, Bogotá, Colombia. ${ }^{2}$ Critical \\ and Intensive Care Medicine, Hospital Universitario Mayor Méderi-Universidad \\ del Rosario, Bogotá, Colombia.
}

Received: 13 December 2019 Accepted: 16 April 2020 Published online: 26 April 2020

\section{References}

1. Nishida O, Arellano R, Cheng DC, DeMajo W, Kavanagh BP (1999) Gas exchange and hemodynamics in experimental pleural effusion. Crit Care Med 27(3):583-587. https://doi.org/10.1097/00003246-199903000-00040

2. Mattison LE, Coppage L, Alderman DF, Herlong JO, Salm SA (1997) Pleural effusions in the medical ICU: prevalence, causes and clinical implications. Chest 111(4):1018-1023. https://doi.org/10.1378/chest.111.4.1018

3. Fartoukh M, Azoulay E, Galliot R, Le Gall JR, Baud F, Chevret S, Schlemmer B (2002) Clinically documented pleural effusions in medical ICU patients: how useful is routine thoracentesis? Chest 121(1):178-184. https://doi. org/10.1378/chest.121.1.178

4. Labidi M, Baillot R, Dionne B, Lacasse Y, Maltais F, Boulet LP (2009) Pleural effusions following cardiac surgery: prevalence, risk factors, and clinical features. Chest 136(6):1604-1611. https://doi.org/10.1378/chest.09-0689

5. Razazi K, Boissier F, Neuville M, Jochmans S, Tchir M, May F, de Prost N, Brun-Buisson C, Carteaux G, Mekontso Dessap A (2018) Pleural effusion during weaning from mechanical ventilation: a prospective observational multicenter study. Ann Intensive Care. https://doi.org/10.1186/s1361 3-018-0446-y

6. Vetrugno L, Bignami E, Orso D, Vargas M, Guadagnin GM, Saglietti F, Servillo G, Volpicelli G, Navalesi P, Bove T (2019) Utility of pleural effusion drainage in the ICU: An updated systematic review and META-analysis. J Crit Care 52:22-32. https://doi.org/10.1016/j.jcrc.2019.03.007

7. Brogi E, Gargani L, Bignami E, Barbariol F, Marra A, Forfori F, Vetrugno L (2017) Thoracic ultrasound for pleural effusion in the intensive care unit: a narrative review from diagnosis to treatment. Crit Care. https://doi. org/10.1186/s13054-017-1897-5

8. Thomsen TW, DeLaPena J, Setnik GS (2006) Videos in clinical medicine. Thoracentesis. The New Engl J Med 355(15):e16. https://doi.org/10.1056/ nejmvcm053812

9. Hooper C, Lee YCG, Maskell N (2010) Investigation of a unilateral pleural effusion in adults: British Thoracic Society pleural disease guideline 2010. Thorax. https://doi.org/10.1136/thx.2010.136978

10. Seneff MG, Corwin RW, Gold LH, Irwin RS (1986) Complications associated with thoracocentesis. Chest 90(1):97-100. https://doi.org/10.1378/ chest.90.1.97

11. Ingelfinger JR, Feller-Kopman D, Light R (2018) Pleural disease. N Engl J Med 378(8):740-751. https://doi.org/10.1056/nejmra1403503

12. Havelock T, Teoh R, Laws D, Gleeson F (2010) Pleural procedures and thoracic ultrasound: British Thoracic Society pleural disease guideline 2010. Thorax. https://doi.org/10.1136/thx.2010.137026

13. Xirouchaki N, Magkanas E, Vaporidi K, Kondili E, Plataki M, Patrianakos A, Akoumianaki E, Georgopoulos D (2011) Lung ultrasound in critically ill patients: Comparison with bedside chest radiography. Intensive Care Med 37(9):1488-1493. https://doi.org/10.1007/s00134-011-2317-y

14. Brogi Etrusca, Bignami E, Sidoti A, Shawar M, Gargani L, Vetrugno L, Volpicelli G, Forfori F (2017) Could the use of bedside lung ultrasound reduce the number of chest $\mathrm{x}$-rays in the intensive care unit? Cardiovasc Ultrasound 15(1):23. https://doi.org/10.1186/s12947-017-0113-8

15. Usta E, Mustafi M, Ziemer G (2010) Ultrasound estimation of volume of postoperative pleural effusion in cardiac surgery patients. Interact Cardiovasc Thorac Surg 10(2):204-207. https://doi.org/10.1510/icvts.2009.22227 3

16. Balik M, Plasil P, Waldauf P, Pazout J, Fric M, Otahal M, Pachl J (2006) Ultrasound estimation of volume of pleural fluid in mechanically ventilated patients. Intensive Care Med 32(2):318-321. https://doi.org/10.1007/ s00134-005-0024-2
17. Vetrugno L, Brogi E, Barbariol F, Forfori F, Bignami E (2018) A message in the bottle. Anesthesiol J Am Soc Anesthesiol 128(3):677. https://doi. org/10.1097/aln.0000000000002039

18. Vetrugno L, Bove T (2018) Lung ultrasound estimation of pleural effusion fluid and the importance of patient position. Ann Intensive Care 8(1):8-10. https://doi.org/10.1186/s13613-018-0471-x

19. Vignon $P$, Chastagner C, Berkane V, Chardac E, François B, Normand S, Bonnivard M, Clavel M, Pichon N, Preux PM, Maubon A, Gastinne H (2005) Quantitative assessment of pleural effusion in critically ill patients by means of ultrasonography. Crit Care Med 33(8):1757-1763. https://doi. org/10.1097/01.ccm.0000171532.02639.08

20. Vetrugno L, Guadagnin GM, Barbariol F, D'Incà S, Delrio S, Orso D, Girometti R, Volpicelli G, Bove T (2019) Assessment of pleural effusion and small pleural drain insertion by resident doctors in an intensive care unit: an observational study. Clin Med Insights Circ Respir Pulm Med. https://doi. org/10.1177/1179548419871527

21. Volpicelli G, Elbarbary M, Blaivas M, Lichtenstein DA, Mathis G, Kirkpatrick AW, Melniker L, Gargani L, Noble VE, Via G, Dean A, Tsung JW, Soldati G, Copetti R, Bouhemad B, Reissig A, Agricola E, Rouby JJ, Arbelot C, Liteplo A, Sargsyan A, Silva F, Hoppmann R, Breitkreutz R, Seibel A, Neri L, Storti E, Petrovic T, International Liaison Committee on Lung Ultrasound (ILC-LUS) for International Consensus Conference on Lung Ultrasound (ICC-LUS) (2012) International evidence-based recommendations for point-ofcare lung ultrasound. Intensive Care Med 38(4):577-591. https://doi. org/10.1007/s00134-012-2513-4

22. Vetrugno L, Guadagnin GM, Orso D, Boero E, Bignami E, Bove T (2018) An easier and safe affair, pleural drainage with ultrasound in critical patient: a technical note. Crit Ultrasound J 10(1):1-10. https://doi.org/10.1186/ s13089-018-0098-z

23. Mokotedi CM, Balik M (2017) Is the mechanism of re-expansion pulmonary oedema in a heart-lung interaction? BMJ Case Rep 2017:1-5. https:// doi.org/10.1136/bcr-2017-219340

24. Barnes TW, Morgenthaler TI, Olson EJ, Hesley GK, Decker PA, Ryu JH (2005) Sonographically guided thoracentesis and rate of pneumothorax. J Clin Ultrasound 33(9):442-446. https://doi.org/10.1002/jcu.20163

25. Raptopoulos V, Davis LM, Lee G, Umali C, Lew R, Irwin RS (1991) Factors affecting the development of pneumothorax associated with thoracentesis. Am J Roentgenol 156(5):917-920. https://doi.org/10.2214/ ajr.156.5.2017951

26. Gervais DA, Petersein A, Lee MJ, Hahn PF, Saini S, Mueller PR (1997) USguided thoracentesis: requirement for postprocedure chest radiography in patients who receive mechanical ventilation versus patients who breathe spontaneously. Radiology 204(2):503-506. https://doi. org/10.1148/radiology.204.2.9240544

27. Petersen S, Freitag M, Albert W, Tempel S, Ludwig K (1999) Ultrasoundguided thoracentesis in surgical intensive care patients. Intensive Care Med 25(9):1029. https://doi.org/10.1007/s001340051004

28. Lichtenstein D, Hulot JS, Rabiller A, Tostivint I, Mezière G (1999) Feasibility and safety of ultrasound-aided thoracentesis in mechanically ventilated patients. Intensive Care Med 25(9):955-958. https://doi.org/10.1007/ s001340050988

29. Mayo PH, Goltz HR, Tafreshi M, Doelken P (2004) Safety of ultrasoundguided thoracentesis in patients receiving mechanical ventilation. Chest 125(3):1059-1062. https://doi.org/10.1378/chest.125.3.1059

30. Goligher EC, Leis JA, Fowler RA, Pinto R, Adhikari NKJ, Ferguson ND (2011) Utility and safety of draining pleural effusions in mechanically ventilated patients: a systematic review and meta-analysis. Crit Care. https://doi. org/10.1186/cc10009

31. Vetrugno L, Volpicelli G, Barbariol F, Toretti I, Pompei L, Forfori F, Della Rocca G (2016) Phantom model and scoring system to assess ability in ultrasound-guided chest drain positioning. Crit Ultrasound J 8(1):1-7. https://doi.org/10.1186/s13089-016-0038-8

\section{Publisher's Note}

Springer Nature remains neutral with regard to jurisdictional claims in published maps and institutional affiliations. 